\title{
Gut
}

Leading article

\section{Why is epidermal growth factor present in the gut lumen?}

Epidermal growth factor (EGF) is a potent mitogen which is continuously secreted into the gut lumen. The sequence and structure of EGF and its receptor have been known for many years. In addition, numerous studies have been performed which are starting to unravel the events which occur after EGF meets its receptor. Despite the great number of papers that have been published in this field, the physiological role of luminal EGF is still unclear. Why is this? In this article we discuss the various methods which have been used to examine the function of EGF in vitro and in vivo and discuss the limitations of these approaches. We also discuss the potential value of EGF as a therapeutic target for the treatment of human gastrointestinal disease.

\section{Background to EGF and its receptor}

EGF is a 53 amino acid peptide (MW 6400) which is secreted into the gut lumen by the salivary glands, Brunner's glands of the duodenum, and also by the ulcer associated cell lineage (UACL) - a recently identified glandular structure induced at sites of injury. ${ }^{12}$ Its concentration in gastric juice is about $500 \mathrm{ng} / \mathrm{l}$, while urine concentrations are about one tenth of this. ${ }^{34}$ Circulating concentrations of EGF are extremely low and much of this circulating EGF is bound to platelets. The human EGF receptor has been cloned and is a $170 \mathrm{kDa}$ protein that consists of a cell surface ligand binding domain, a single hydrophobic transmembrane domain, and a cytoplasmic tyrosine kinase domain. When EGF binds to its receptor it results in clustering, dimerisation, and internalisation of the receptor-ligand complex. Although this protein is called the EGF receptor, it is important to note that it also binds transforming growth factor $\alpha$, amphiregulin, and heparin binding EGF. The relative physiological importance of these different ligands is unclear. This article focuses predominantly on EGF. An excellent detailed review of EGF related peptides has been published by Barnard et $a .^{5}$

\section{Actions of EGF}

EGF is a potent stimulant of proliferation for a variety of cell lines in vitro. In addition, many studies have shown that systemic administration of EGF results in acid suppression and cytoprotective action against a variety of acid dependent and independent models of gastric ulceration. Because most of the EGF is present in the lumen and circulating concentrations are low, however, it is probable that any major physiological role of EGF will be mediated via luminal EGF and not via the systemic circulation. Four main approaches have been used to examine the function of luminal EGF:

\section{INTRALUMINAL ADMINISTRATION OF EGF}

Studies in which EGF has been administered intraluminally initially seem to be the most appropriate. Most of these have been performed using rats, and there is a consensus developing that luminal EGF is active in stimulating gut growth in the neonatal rat and also in the damaged bowel. Whether administration of luminal EGF to the undamaged bowel stimulates growth, however, is uncertain. The reasons for the apparently conflicting results are unclear but differences in dosage used, species studied, and bolus versus continuous infusion of EGF may all be important. Equivalent studies in humans have not been performed. When interpreting the results of studies examining the effect of luminally administered EGF, it is important that the details of the experimental protocol are considered. For example, studies examining the effect of luminal EGF on intestinal growth in intestine that has recently undergone resection may be influenced by the increased gut permeability caused by surgical handling and the presence of an anastomosis. Caution has to be shown in interpreting these results in terms of 'normal' physiology.

The importance of considering the experimental design is shown by our studies on the stability of growth factors in the gastrointestinal lumen. We have shown that luminal EGF is susceptible to proteolytic digestion in the stomach (by pepsin) but that this is reduced considerably if the $\mathrm{pH}$ is raised above $4 .^{3}$ Protocols involving administration of acid suppressants may therefore result in an appreciable change in luminal EGF bioactivity.

Differences in the diet of the animals may also be important as we have shown that EGF is also susceptible to degradation by pancreatic proteases present in the small intestine. ${ }^{6}$ Luminal EGF is rapidly destroyed in the small intestine of fasted, but not fed, rats. This is probably because the food proteins (in the fed rats) act as competitive substrates for the luminal proteases and the digestion 
of luminal EGF is therefore decreased. Concentrations of endogenous and exogenously administered EGF will therefore vary according to whether the animals are fasted or fed and the type of diet used. We reported that systemic, but not luminal EGF, was trophic to the intestine of parenterally fed rats $^{7}$ and this is often quoted as a key paper showing the lack of effect of luminal EGF. However, we have subsequently shown that the intraluminally infused EGF was rapidly digested by residual proteases and was therefore not available to stimulate growth. We have also shown that if EGF is co-infused with soya bean trypsin inhibitor (to reduce luminal degradation of the EGF) it does stimulate growth of the small intestine. ${ }^{8}$ However, when interpreting our latest results it emerges that parenterally fed animals probably have increased gut permeability which might allow EGF to reach its receptor, even if the EGF receptor is not present on the apical membranes (see later). These types of experiments should be interpreted with caution!

\section{EXAMINATION OF THE DISTRIBUTION OF THE}

\section{EGF/RECEPTOR}

If luminal EGF is important in maintaining gut growth, one would expect the receptor to be present on the apical (luminal) membranes. Various techniques have been used to examine this question, including immunocytochemistry, Western blotting of microvillus preparations, and autoradiography. Most of these studies have examined the distribution of the EGF receptor in animal models, especially the rat. A recent paper by Thompson et al ${ }^{9}$ reported that in the adult and neonatal rat, the EGF receptor is restricted to the basolateral membranes. This suggests that the reason luminal EGF is active in rat neonatal gut is because the increased permeability of the neonatal bowel allows passage of luminal EGF to its receptor on the basolateral membranes. This is an important result as most studies have been performed under the assumption that the distribution of the EGF receptor might alter as the rat matures. In contrast to these findings, studies using autoradiographic localisation of the EGF receptor in the pig intestine suggests an apical (luminal) distribution. ${ }^{10}$ If EGF receptors are present on the apical membranes, they probably only constitute a small proportion of the number seen on the basolateral membranes. Particular care must be taken to prevent false negative results due to insufficient sensitivity, and conversely, that contamination of apical membrane preparations with relatively small amounts of basolateral membranes does not produce false positive results. Our recent studies examining the distribution of the EGF receptor in the human gastrointestinal tract (using immunohistochemistry, electron microscopy, and Western blotting techniques) suggest that in the human adult the receptor is restricted to the basolateral membranes. ${ }^{11}$ Preliminary immunolocalisation studies suggest that the distribution may be different in the damaged human bowel. ${ }^{12}$

\section{EXAMINATION OF THE EFFECT OF REDUCING}

INTRALUMINAL EGF CONCENTRATIONS BY REMOVAL OF THE SALIVARY GLANDS

Removal of the salivary glands of rats markedly reduces the concentrations of EGF present in gastric juice. Despite this reduction, gastric acid secretion does not rise and spontaneous ulceration does not occur. ${ }^{13}$ However, several studies suggest that gastric mucosal growth is reduced by this procedure (for example, ref $^{14}$ ) although the small intestine and colon are probably not affected.1415 However, to complicate matters further, $\mathrm{Li}$ and co-workers have reported that removal of salivary glands does not cause intestinal atrophy but, somewhat confusingly, that artificially induced salivary hypersecretion stimulates small intestinal growth. ${ }^{15}$ In contrast to the relatively small effect that sialadenectomy has on the non-damaged bowel, there is a general consensus that artificially-induced ulcers are more extensive and take longer to heal in rats which have undergone sialadenectomy (for example, ref $^{13}$ ). Caution is needed before extrapolating these results to humans, although patients with gastric ulceration do have reduced levels of gastric juice EGF. ${ }^{16}$

PRODUCTION OF KNOCK OUT MICE

Rapid advances in molecular biological techniques now allow animal models to be produced in which a particular gene of interest is disrupted (or knocked out) in every cell of the body. These animals are then examined to predict the function of the targeted gene. Initially it was assumed that the development of an EGF receptor 'knock out' mouse model would make a major contribution to establishing the function of EGF in vivo. This model has recently been produced but, in at least one strain, the animals die within a few days of birth due to respiratory disease and intestinal ulceration. ${ }^{17}$ While this result emphasises the importance of the EGF receptor, it does not allow us to define the role of EGF, which is only one of the many ligands binding to this receptor. Other groups have developed their own EGF receptor knockout mice (using different mice strains) but in contrast to the findings of Miettinenpj et al, these animals do not get severe colitis. ${ }^{18} 19$ These findings emphasise the need to show caution in extrapolating results from mice to humans. To determine which of the EGF receptor ligands are physiologically important, each needs to be individually 'knocked out'. Transforming growth factor $\alpha$ knockout mice have already been produced and the gastrointestinal tract seems normal. ${ }^{20}$ The production of EGF knock out mice is awaited with interest.

\section{Possible clinical value of recombinant EGF}

Taken together, the studies performed so far suggest that the major role of EGF is to stimulate repair at sites of injury and that it plays a relatively minor role in the maintenance of normal gut growth in the human adult. However, administration of recombinant EGF via the lumen may be clinically useful for the treatment of gastrointestinal ulceration distal to the duodenum. Acid suppressants and Helicobacter pylori eradication therapy are very effective treatments for peptic ulceration. However, the treatment of inflammatory bowel disease, chemotherapy induced mucositis, and necrotising enterocolitis is still suboptimal. Preliminary studies suggest that recombinant EGF may be useful in the treatment of all these conditions. ${ }^{21}$ Although nearly all studies have examined the effect of systemic EGF on these conditions, treatment with luminal EGF may well provide a safer alternative as the bowel is damaged (with increased permeability) and luminal EGF is therefore likely to reach its receptor. If clinical trials examining the potential value of luminal EGF are to be performed, co-administration of acid suppressants (to reduce gastric digestion), protease inhibitors (to reduce proteolysis by pancreatic proteases), or trefoil peptides (which act synergistically with EGF in the healing process, ${ }^{22}$ may well improve its clinical effectiveness.

\section{Conclusions}

The jury is still out on the role of luminal EGF in the normal gastrointestinal tract. Recent evidence, however, 
suggests that its major function is to act as a 'luminal surveillance' peptide, ${ }^{23}$ which is available to stimulate repair and that it is not of major importance in maintaining normal gut growth. Recombinant EGF administered via the gut lumen could still prove a valuable tool for the treatment of gastrointestinal ulceration. Perhaps the old term for EGF, 'epidermal healing factor' or EHF, was more appropriate after all!

Department of Gastroenterology,

R J PLAYFORD

Leicester General Hospital,

Leicester LE5 4PW

Histopathology Unit,

N A WRIGHT

Imperial Cancer Research Fund,

London

Correspondence to: Professor R J Playford.

RJP was funded by the MRC. Thanks to Sir Francis Avery Jones for his helpful comments.

1 Heitz PU, Kasper M, Van Nordan S, Polak JM, Gregory H, Pearse GE. Immunohistochemical localisation of urogastrone to human duodenal and submaxially glands. Gut 1978; 19: 408-13.

2 Wright NA, Pike C, Elia G. Induction of a novel epidermal growth factorWright NA, Pike C, Elia G. Induction of a novel epidermal growth factor-
secreting cell lineage by mucosal ulceration in gastrointestinal stem cells. Nature 1990; 343: 82-5.

3 Playford RJ, Marchbank T, Calam J, Hansen FH. EGF is digested to smaller, less active, forms in acidic gastric juice. Gastroenterology 1995; 108: 92-101.

4 Joh T, Itoh M, Katsumi K, Yokoyama Y, Takeuchi T, Kato T, Wada Y, Tanaka R, Physiological concentrations of human epidermal growth factor; use of a sensitive enzyme immunoassay. Clin Chim Acta 1986; 158: 81-90.

5 Barnard JA, Beauchamp RD, Russell WE, Dubois RN, Coffey RJ, Epidermal growth factor-related peptides and their relevance

testinal pathophysiology. Gastroenterology 1995; 108: $564-80$.
6 Playford RJ, Watanaba P, Woodman AC, Deprez PH, Calam J. Effect of luminal growth factor preservation on intestinal growth. Lancet 1993; 341: 843-8.
7 Goodlad RA, Wilson TJG, Lenton W, Gregory H, McClagh KG, Wright NA. Intravenous but not intragastric urogastrone (EGF) is trophic to the intestine of parenterally fed rats. Gut 1987; 28: 573-82.

8 Marchbank T, Goodlad RA, Lee CY, Playford RJ. Rapid communication: Luminal epidermal growth factor is trophic to the small intestine of parenterally fed rats. Clin Sci 1995; 89: 117-20.

9 Thompson JF, Van den Berg M, Stokkers PCf. Developmental regulation of epidermal growth factor receptor kinase in rat intestine. Gastroenterology 1994; 107: 1278-87.

10 Kelly D, McFadyen M, King TP, Morgan PJ. Characterisation and localisation of the epidermal growth factor receptor in the jejunum of the localisation of the epidermal growth factor receptor in the jeju

11 Playford RJ, Hanby AM, Goodlad RA, Gschmeissner S, Patel K, Peiffer LP McGarrity T. The EGF-receptor is present on the basolateral, but not the apical, surface of enterocytes in the human gastrointestinal tract. Gastroenterology 1995; 108: A747.

12 Wright NA, Poulsom R, Stamp G, van Noorden S, Sarraf C, Elia G, et al. Trefoil peptide gene expression in gastrointestinal epithelial cells in inflammatory bowel disease. Gastroenterology 1993; 104: 12-20.

13 Skov-Olsen P, Poulsen SS, Therkelsen K, Nexo E. Effect of sialoadenectomy and synthetic human urogastrone on healing of chronic gastric ulcers in rats. Gut 1986; 27: 1443-9.

14 Skinner KA, Soper BD, Tepperman BL. Effect of sialoadenectomy and salivary gland extracts on gastrointestinal mucosal growth and gastrin salivary gland extracts on gastrointestinal mucos
levels in the rat. $\mathcal{F}$ Physiol (Lond) 1984; 351: 1-12.

15 Li AKC, Schattenkerk ME, Huffman RG, Ross JS, Malt RA. Hypersection of submandibular saliva in male mice: tropic response in small intestine. Gastroenterology 1983; 84: 949-55.

16 Hansen G, Sinha MP. Gastric ulcer is accompanied by a decrease of epidermal growth factor in gastric juice and saliva. $\mathcal{f}$ Clin Chem Clin Biochem 1989; 27: 539-45.

17 Miettinen PJ, Berger JE, Meneses J, Phung Y, Pedersen RA, Werb Z, et al. Epithelial immaturity and multiorgan failure in mice lacking epidermal growth factor receptor. Nature 1995; 376: 337-41.

18 Threadgill DW, Dlugosz AA, Hansen LA, Tennenbaum T, Lichti U, Yee $\mathrm{D}$, et al. Targeted disruption of the mouse EGF receptor: effect of genetic background on mutant phenotype. Science 1995; 269: 230-4.

19 Sibilia M, Wagner EF. Strain dependant epithelial defects in mice lacking Sibilia M, Wagner EF. Strain dependant epithe
the EGF receptor. Science 1995; 269: 234-8.

20 Luetteke NC, Qiu TH, Oliver P, Smithies O, Less DC. TGF alpha deficiency results in hair follicle and eye abnormalities in targeted and waved-1 mice. Cell 1993; 73: 263-78.

21 Sullivan PB, Brueton MJ, Tabara Z, Goodlad RA, Lee CY, Wright NA Epidermal growth factor in necrotising enteritis. Lancet 1991; 338: 53-4

22 Chinery R, Playford RJ. Rapid communication: combined intestinal trefoil factor and epidermal growth factor is prophylatic against indomethacininduced gastric damage in the rat. Clin Sci 1995; 88: 401-3.

23 Playford RJ. The role of peptides in mucosal integrity and repair. Gut 1995; 37: 595-7. 